\title{
Comparative study of efficacy and adverse effects of different doses of vaginal misoprostol for cervical ripening 10-12 hours before diagnostic hysteroscopy
}

\author{
Taru Gupta, Syed Nawaz Ahmad, Sonu Kumari*
}

Department of Obstetrics and Gynecology, ESI-PGIMSR, Basaidarapur, New Delhi, India

Received: 06 January 2018

Accepted: 31 January 2018

\author{
*Correspondence: \\ Dr. Sonu Kumari, \\ E-mail: grewalsonu264@gmail.com
}

Copyright: () the author(s), publisher and licensee Medip Academy. This is an open-access article distributed under the terms of the Creative Commons Attribution Non-Commercial License, which permits unrestricted non-commercial use, distribution, and reproduction in any medium, provided the original work is properly cited.

\begin{abstract}
Background: Hysteroscopy first described by Panteleoni in 1869 has evolved into a standard procedure for the diagnosis and treatment of intrauterine pathologies such as polyps, fibroids, septae, adhesions, evaluation of abnormal uterine bleeding, evaluation and treatment of infertility, removal of an intrauterine device or foreign body. Present study was carried out to compare the efficacy and complications different doses of vaginal misoprostol for cervical ripening 10-12 hours before diagnostic hysteroscopy.

Methods: It was a prospective and interventional, double-blinded randomized comparative study. Sixty women, fulfilling the inclusion criteria, requiring diagnostic hysteroscopy for evaluation of infertility were enrolled. The study subjects randomly received either $200 \mu \mathrm{g}$ (group 1) or $400 \mu \mathrm{g}$ (group 2) of vaginal misoprostol 10-12 hours before hysteroscopy with equal number of subjects in both the groups. Hysteroscopy was performed with a standard rigid 6 $\mathrm{mm}$ and 300 hysteroscope. The largest dilator that could be inserted without resistance was recorded as the baseline cervical dilatation. The ease of dilatation was recorded on a 5 point LIKERT scale. Procedural time was measured as time taken from the beginning of cervical dilatation to the visualisation of the uterine cavity.

Results: The mean base line cervical width in group 1 was $6.41 \pm 0.29 \mathrm{~mm}$ while in group 2 it was $6.43 \pm 0.21 \mathrm{~mm}$ $(\mathrm{p}=0.084)$. In group $1,26.6 \%$ patients had very easy entry, $53.4 \%$ had easy entry while in group $2,30 \%$ patients had very easy entry, $43.4 \%$ had easy entry. The mean procedural time $35.5 \pm 6.9$ seconds in group 1 and $33.2 \pm 6.8$ seconds in group $2(\mathrm{p}=0.212)$. Adverse effects like abdominal pain, vaginal bleeding, shivering and fever were observed more often in group 2 compared to group $1(\mathrm{p}=0.038)$.

Conclusions: Two hundred microgram of vaginal misoprostol is safer and equally effective as $400 \mu \mathrm{g}$ for cervical ripening when used 10-12 hours before diagnostic hysteroscopy.
\end{abstract}

Keywords: Cervical width, Hysteroscopy, Misoprostol

\section{INTRODUCTION}

Hysteroscopy first described by Panteleoni in 1869 has evolved into a standard procedure for the diagnosis and treatment of intrauterine pathologies such as polyps, fibroids, septae, adhesions, evaluation of abnormal uterine bleeding, evaluation and treatment of infertility, removal of an intrauterine device or foreign body. ${ }^{1}$ Operative hysteroscopy usually requires a dilatation of 9$10 \mathrm{~mm}$ and for diagnostic procedures dilatation of $6 \mathrm{~mm}$ is generally sufficient. Achieving this degree of dilatation of the non-gravid cervix is always tedious and sometimes impossible without prior cervical ripening. Almost half of hysteroscopic complications are related to difficult hysteroscopic cervical entry. Potential complications 
include cervical tears, creation of a false passage in the cervical stroma, perforation of the uterine cervix or uterus itself. The incidence of these complications could be reduced if the cervix is ripened before the procedure. Prostaglandins are the most commonly used agents for this purpose. Prostaglandins can be used both vaginally as well as orally for cervical ripening. Vaginally administered misoprostol before hysteroscopy makes cervical dilatation easy and helps avoid complications. As misoprostol is cheaper, widely available, easy to use, having a long shelf-life, it has been employed as a cervical ripening agent before hysteroscopy in order to reduce the complications occurring during cervical dilatation. After administration, misoprostol gets converted into its active metabolite misoprostol acid. The main actions include gastrointestinal cyto-protection (approved therapeutic indication) and uterotonicity. It sometimes also causes diarrhoea and abdominal pain which are undesirable. Although the efficacy of misoprostol for cervical ripening before hysteroscopy has well been acknowledged but there are only a few studies to compare different dose of the drug for this purpose.

We designed this study to evaluate and compare the efficacy and safety of $200 \mu \mathrm{g}$ and $400 \mu \mathrm{g}$ of vaginal misoprostol on cervical ripening inserted 10-12 hours before diagnostic hysteroscopy, with regard to baseline cervical width before procedure, ease of cervical entry, procedural time, adverse effects and complications.

\section{METHODS}

This prospective and interventional, double-blinded randomized comparative study conducted at a tertiary care multi-specialty hospital in New Delhi, India after approval from the Institutional Ethics Committee. The procedures followed were in accordance with the ethical standards of the responsible committee on human experimentation (institutional) and with the Helsinki Declaration of 1975 and revised in 2008(5). Sixty women requiring diagnostic hysteroscopy for evaluation of infertility after written and informed consent were enrolled in the study. Patients with contraindications to prostaglandins like asthma, glaucoma and previous cervical or uterine surgery were not included in the study population. Study subjects randomly received either $200 \mu \mathrm{g}$ (group 1) or $400 \mu \mathrm{g}$ (group 2) of vaginal misoprostol 10-12 hours before diagnostic hysteroscopy with equal number of subjects in both the groups. Study subjects were randomised to either of the two groups by computerised block randomisation technique. Diagnostic hysteroscopy was done under general anaesthesia using a standard rigid $6 \mathrm{~mm}$ and 300 hysteroscope. Initially an attempt to insert the hysteroscope directly into the cervical canal was made and if this failed then serial dilatation using Hegar's dilators up till number 6 was done. The largest dilator that negotiated cervical canal without resistance was recorded as the baseline cervical dilatation. The ease of dilatation was recorded on a 5 point LIKERT scale (1=very difficult, $2=$ difficult, $3=$ fair, 4 = easy, 5 = very easy). Procedural time was measured as time taken from the beginning of cervical dilatation to the visualisation of the uterine cavity. Side effects like fever and shivering, abdominal pain, diarrhoea and vomiting and vaginal bleeding were compared between the two groups. Patients were monitored for 24 hours after surgery and were given doxycycline $100 \mathrm{mg}$ twice a day for 7 days starting from the day of the procedure.

\section{RESULTS}

The mean age of the patient in the study population was $29.6 \pm 5$.91years. Approximately $55 \%$ of the patients were educated higher than 10th grade. All the study subjects underwent hysteroscopy for infertility evaluation. In our study nausea was perceived by significantly higher number of patients in group $2(33.4 \%)$ compared to only $10 \%$ group 1 ( $\mathrm{p}$ value $=0.028$ ). The incidence and severity of nausea was found to be dose dependent. Abdominal pain was perceived only by $13.4 \%$ patients in group 1 as opposed to $43.4 \%$ in group 2 and the difference was found to be statistically significant $(\mathrm{p}$ value $=0.010)$.

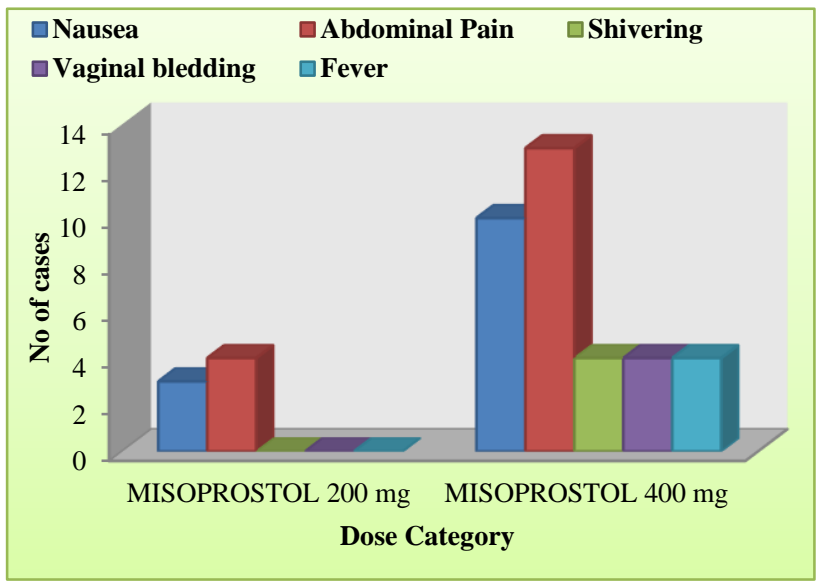

Figure 1: Comparison of side effects of two separate doses of misoprostol in the study population.

Four patients in group 2 experienced vaginal bleeding while as none of the patients in group 1 experienced vaginal bleeding $(\mathrm{p}=0.038 \%)$. Another four patients in group 2 experienced fever and shivering and none in group 1 had such complaints $(\mathrm{p}=0.038 \%$ ) (Figure 1$)$.

The mean baseline cervical width was $6.41 \pm 0.296 \mathrm{~mm}$ in group 1 and $6.43 \pm 0.217 \mathrm{~mm}$ in group 2 and the difference between the two was found to be statistically insignificant $(\mathrm{p}$ value $=0.084)($ Table 1$)$.

The mean procedural time from beginning of cervical dilatation till visualization of uterine cavity was $35.5 \pm 6.9$ seconds in group 1 and $33.2 \pm 6.8$ seconds in group 2 (p value $=0.212$ ). Thus, increasing the dose of misoprostol didn't result in any significant decrease in procedural time (Table 1). 
Table 1: Comparison of baseline cervical width and procedural time within two study groups.

\begin{tabular}{|c|c|c|c|c|c|c|}
\hline Parameters & $\begin{array}{l}\text { Group (misoprostol } \\
\text { dose in } \mu \mathrm{g} \text { ) }\end{array}$ & $\begin{array}{l}\text { Number of } \\
\text { cases (n) }\end{array}$ & Mean & $\begin{array}{l}\text { Standard } \\
\text { deviation }\end{array}$ & $\begin{array}{l}\text { Standard } \\
\text { error of mean }\end{array}$ & P-value \\
\hline \multirow{2}{*}{$\begin{array}{l}\text { Baseline cervical width } \\
\text { (millimetres) }\end{array}$} & Group1 (200) & 30 & 6.4167 & 0.29605 & 0.05405 & \multirow{2}{*}{0.804} \\
\hline & Group 2 (400) & 30 & 6.4333 & 0.21709 & 0.03963 & \\
\hline \multirow{2}{*}{$\begin{array}{l}\text { Procedural time } \\
\text { (seconds) }\end{array}$} & Group1 (200) & 30 & 35.5000 & 6.90202 & 1.26013 & \multirow{2}{*}{0.212} \\
\hline & Group 2 (400) & 30 & 33.2667 & 6.80737 & 1.24285 & \\
\hline
\end{tabular}

Table 2: Frequency distribution of the patients according to the ease of hysteroscopic entry.

\begin{tabular}{|c|c|c|c|c|c|c|c|}
\hline \multirow{2}{*}{\multicolumn{2}{|c|}{ Group (Drug dose in $\mu g$ ) }} & \multicolumn{4}{|c|}{$\begin{array}{l}\text { Ease of hysteroscopic entry as measured on } \\
\text { the } 5 \text { point Likert's scale }\end{array}$} & \multirow[t]{2}{*}{ Total } & \multirow{2}{*}{$\begin{array}{l}\text { P- } \\
\text { value }\end{array}$} \\
\hline & & Very Easy & Easy & Fair & Difficult & & \\
\hline \multirow{2}{*}{ Group 1 (200 mg) } & Count & 8 & 16 & 3 & 3 & 30 & \multirow{6}{*}{0.833} \\
\hline & Percentage & 26.6 & 53.4 & 10.0 & 10.0 & 100 & \\
\hline \multirow{2}{*}{ Group 2 (400 mg) } & Count & 9 & 13 & 3 & 5 & 30 & \\
\hline & Percentage & 30.0 & 43.4 & 10.0 & 16.6 & 100 & \\
\hline \multirow{2}{*}{ Total } & Count & 17 & 29 & 6 & 8 & 60 & \\
\hline & Percentage & 28.3 & 48.3 & 10.0 & 13.3 & 100.0 & \\
\hline
\end{tabular}

Out of 30 patients in group $1,26.6 \%$ patients had very easy entry, $53.4 \%$ had easy entry, $10 \%$ had fair entry, $10 \%$ had difficult entry while in group 2, 30\% patients had very easy entry, $43.4 \%$ had easy entry, $10 \%$ had fair and $16.6 \%$ had difficult entry. Minor statistically insignificant differences in the ease of endoscopic entry were observed between two study groups ( $\mathrm{p}$ value of 0.833) (Table 2).

None of the patients had any major operative complication during hysteroscopy in terms of perforation, false passage or cervical trauma in either group.

Out of 60 patients, $6(20 \%)$ patients had over-dilatation leading to fluid leakage in group 2 whereas none had over-dilatation in group 1.

\section{DISCUSSION}

Hysteroscopy is considered a minimally invasive approach to visualize and simultaneously treat numerous intrauterine and endo-cervical pathologies. The advantage of this method is diagnosis and treatment under direct vision. $^{2}$ However, associated with hysteroscopy are well known complications like cervical laceration, perforation, false tract formation and haemorrhage..$^{3-5}$

Fortunately, the incidence of these complications can be reduced if the cervix is ripened beforehand. Misoprostol, a prostaglandin E1 analogue, which was initially used for the treatment of peptic ulcers, has been widely used in obstetrics and gynecology because of its ripening effect on cervix. The primary advantages of this drug include its thermo-stability, low cost, and the ease of administration. Further, it can be administered by various routes including oral, sublingual, vaginal and rectal.
Although majority of the studies confirm the role of misoprostol in cervical ripening, not many studies have been conducted to compare the efficacy of different doses of misoprostol for the same.

The mean age of the patients in our study group 1 was $29.6 \pm 5.91$ years and in group 2 was $28.06 \pm 5.37$ years. All the patients were being investigated for infertility. In the study by Bastu E et al in 2013 mean age of the patients was $32.75 \pm 5.37$ years and $30.35 \pm 6.38$ years in two comparative groups, which was comparable to present study groups. ${ }^{6}$

Misoprostol is relatively devoid of major side effects. In group 1of our study only $13.4 \%$ patients experienced abdominal pain after receiving misoprostol in comparison to $43.4 \%$ in group 2 ( $\mathrm{p}$ value $=0.010)$.

In the study by Waleed El-Khayat et al while comparing the efficacy of 200 and $400 \mu \mathrm{g}$ of vaginal misoprostol 3 hours before surgery abdominal pain was observed with a higher frequency in the $400 \mu \mathrm{g}$ misoprostol group compared to $200 \mu \mathrm{g}$ group $(16.7 \%$ versus $6.1 \%) .{ }^{7}$ Over all abdominal pain was perceived less frequently than our study.

The interval time between drug administration and procedure in their study was only 3 hours and that could be the reason for lesser frequency of abdominal cramping in their study. This could further imply that the occurrence of abdominal pain could be dependent on the drug dose as well as the time interval between drug administration and the procedure. To minimize the incidence of abdominal pain without compromising efficacy, lower doses of misoprostol $(200 \mu \mathrm{g})$ could be tried for cervical priming as evidenced by present study. 
In present study nausea was perceived by $33.4 \%$ patients in group 2 compared to only $10 \%$ group 1 (p value $=0.028$ ). Frequency and severity of nausea was directly proportional to the dose of misoprostol.

El Khayat W et al compared the effectiveness of $200 \mu \mathrm{g}$ and $400 \mu \mathrm{g}$ of vaginal misoprostol and found that there was no significant difference in the perception of nausea (1.5\% in each group), however, in their study misoprostol was administered vaginally only 3 hours prior to surgery which could be the reason. ${ }^{7}$

Vahadat et al in their study while evaluating the efficacy of $400 \mu \mathrm{g}$ of vaginal misoprostol 10-12 hours before hysteroscopy also found that nausea was higher in misoprostol group as compared to control, although the difference wasn't statistically significant. ${ }^{8}$

Four patients $(13.4 \%)$ in group 2 in our study experienced vaginal bleeding after administration of misoprostol while as no patient in group 1 had vaginal bleeding ( $p$ value $=0.038$ ). Not many studies comparing the incidence and the amount of vaginal bleeding with different doses of vaginal misoprostol prior to hysteroscopy were available. Vaginal bleeding however was documented by most of the authors with the use of misoprostol irrespective of the route of administration and interval between administration and the procedure. ${ }^{8}$

Four patients (13.4\%) in group 2 had shivering and fever while none had such complaints in group 1 ( $\mathrm{p}$ value = 0.038 ). Vineeta et al in their study documented fever in $9.09 \%$ patients mostly when $400 \mu \mathrm{g}$ misoprostol was administered sublingually. ${ }^{9}$

Although fever and shivering with misoprostol are well documented in literature, not many studies comparing the dose response relationship were available. ${ }^{10}$

Adverse effects of misoprostol like diarrhoea, fever, nausea, mild abdominal pain and bleeding are significantly increased with increasing dose of misoprostol. However, these side effects are generally minor, transient, and well tolerated by patients. Increasing the dose of vaginal misoprostol does not improve the effect on cervical dilatation but does increase the aforementioned side effects.

In addition, misoprostol, when administered vaginally, has fewer side effects compared with oral or sublingual administration. ${ }^{11}$

The primary outcome of the study - mean baseline cervical width was $6.41 \pm 0.296$ and $6.43 \pm 0.217 \mathrm{~mm}$ in groups 1 and 2, respectively (p value 0.084 ). In a metaanalytical study by Hua et al, which included 25 RCTS and total of 2203 women, the mean cervical dilatation was significantly more in the misoprostol group compared to placebo or no medication (mean dilatation $=1.34 \mathrm{~mm} ; 95 \% \mathrm{CI}: 0.55-2.14$ ) irrespective of the route of administration. ${ }^{12}$ Furthermore, mean cervical dilatation in the vaginal misoprostol group was significantly more compared to placebo or no medication (mean dilatation=1.64 mm; 95\%CI: 0.93-2.35). In vaginal misoprostol group it was found that $200 \mu \mathrm{g}$ and $400 \mu \mathrm{g}$ facilitated similar pre-procedural cervical width of $2.20 \mathrm{~mm}$.

In addition, statistically insignificant difference in the mean cervical dilatation was observed in the $800 \mu \mathrm{g}$ (MD $0.16 \mathrm{~mm}$; $95 \% \mathrm{CI}-0.33$ to 0.66 ) or the $1,000 \mu \mathrm{g}$ subgroup (MD $0.60 \mathrm{~mm} ; 95 \% \mathrm{CI}-0.73$ to 1.94 ). The subgroup analysis indicated that the lower doses of 200 or $400 \mu \mathrm{g}$ vaginal misoprostol produced a more beneficial effect in the outcome of cervical width than higher doses. It was concluded from the meta-analysis that lower doses of vaginal misoprostol administered 10-12 hours before hysteroscopy could produce better pre-procedural cervical dilatation and simultaneously alleviate the side effects associated with higher doses of misoprostol.

In this study we aimed to find the best effective low dose of vaginal misoprostol with a good safety profile.

Out of 30 patients in group 1, 26.6\% patients had very easy entry, $53.3 \%$ had easy entry, $10 \%$ had fair entry, $10 \%$ had difficult entry while in group 2, $30 \%$ patients had very easy entry, $43.3 \%$ had easy entry, $10 \%$ had fair and $16.6 \%$ had difficult entry. This could be explained by the fact that 3 patients in group 2 with difficult entry had history of repeated dilatation and evacuation that might have lead to cervical trauma and resultant fibrosis and hence leading to difficult endoscopic entry. Hysteroscopic entry was easy in $90 \%$ of patients in group 1 and $83.4 \%$ in group $2(\mathrm{p}$ value $=0.833)$.

Vineeta et al in their prospective double blind randomized control trial while comparing sublingual and vaginal $400 \mu \mathrm{g}$ of misoprostol found that hysteroscopic entry was easy in $90.91 \%$ patients in the vaginal misoprostol group compared to only $40.91 \%$ in the sublingual misoprostol group ( $\mathrm{p}$ value 0.001$).{ }^{9}$ They concluded that vaginal misoprostol was preferable to sublingual.

Bastu E et al in while comparing $200 \mu \mathrm{g}$ and $400 \mu \mathrm{g}$ of vaginal misoprostol found no significant difference in the ease of hysteroscopic entry between two groups. ${ }^{6}$ In other study by Bakas $\mathrm{P}$ et al in while comparing the effects of $200 \mu \mathrm{g}$ of misoprostol on cervical ripening when it was given orally 12 hours before the before the procedure; vaginally 12 hours before the procedure and vaginally 4 hours before the procedure, found that ease of entry was superior in the vaginal misoprostol group 12 hours before hysteroscopy compared to the other two groups. ${ }^{10}$ This observation was very much concordant with our study. From our study and the existing literature it can be concluded that $200 \mu \mathrm{g}$ of misoprostol administered vaginally 10-12 hours before the procedure is superior to $400 \mu \mathrm{g}$ of vaginal dose. 
The mean procedural time from beginning of cervical dilatation to the visualization of uterine

cavity was $35.5 \pm 6.9$ seconds in group 1 and $33.2 \pm 6.8$ seconds in group 2 , respectively $(\mathrm{p}$ value $=0.212$ ). We didn't find any significant decrease in the procedural time by merely increasing the dose of the misoprostol. There are however studies in literature with contradictory results to ours, like in the study by Waleed et al. ${ }^{6,7}$ There are other studies in literature like Bastu E et al that computed procedural time from the beginning of the endoscopic entry to the end of the operative procedure which included polypectomies etc. Their procedural time couldn't hence be compared to our study.

One unfavourable effect of cervical over-dilatation leading to constant leakage of distension medium was observed in 6 patients $(20 \%)$ in our study in group 2 . This lead to constant leakage of the distension medium and required the use of additional instrumentation on cervix for conduction of procedure, though it had no any major consequence. No such complication is however documented in medical literature till date.

No major complications were encountered by us.

\section{CONCLUSION}

No statistically significant differences were observed on cervical ripening when higher doses of misoprostol were used. Lower doses of misoprostol could produce similar cervical changed and simultaneously avoid adverse effects.

\section{Funding: No funding sources}

Conflict of interest: None declared

Ethical approval: The study was approved by the Institutional Ethics Committee

\section{REFERENCES}

1. Hasen A, Zeynep H, Esra T, Turgut V. Comparison of vaginal misoprostol and dinoprostone for cervical ripening before diagnostic hysteroscopy in nulliparous women. Fertil Sterli. 2015;103:1326-31.

2. Fard SA, Ebrahimi FS, Montazeri F, Mashrabi O. Diagnostic features and therapeutic consequences of hysteroscopy in women with abnormal uterine bleeding and abortion. Am J Applied Sci. 2012;9:137.

3. Jansen FW, Vredevoogd CB, Ulzen KV, Herman J, Trimbos JB, Trimbos- Kemper TC. Complications in hysteroscopy: a prospective multicenter study. Obstet Gynecol. 2000;96:266-70.

4. Loffer FD. Complications of hysteroscopy-their cause, prevention, and correction. J Am Assoc Gynecol Laparosc. 1995;3:11-26.

5. Vilos GA, Vilos EC, King JH. Experience with 800 hysteroscopic endometrial ablations. J Am Assoc Gynecol Laparosc. 1996;4:33-8.

6. Bastu E, Celik C, Nehir A, Dogan M, Yuksel B, Ergun B. Cervical priming before diagnostic operative hysteroscopy in infertile women: a randomized, double-blind, controlled comparison of 2 vaginal misoprostol doses. Int Surg. 2013 May;98(2):140-4.

7. El-Khayat W, Elsawah H, Idris O. A double-blind randomized controlled trial of two different doses of misoprostol for cervical priming prior to office hysteroscopy. Middle East Fertil Soc J. 2015 Mar $31 ; 20(1): 1-5$.

8. Vahdat M, Kashi AM, Saberifard M, Chaichian S. Determination of the effect of vaginal misoprostol in cervical ripening before the operative hysterocopy in premenopausal women without history of normal vaginal delivery. J Minim Invasive Surg Sci. 2013 Sep;2(4).

9. Vineeta, K Abhinav, Nagar O, K Richa, N Subrata. A randomized, double-blind, placebo- controlled comparison of sublingual and vaginal misoprostol. IOSR-JDMS. 2015;14(4):49-53.

10. Bakas P, Hassiakos D, Liapis A, Creatsa M, Konidaris S, Gregoriou O. Misoprostol for cervical ripening before diagnostic hysteroscopy in nulliparous women. Int $\mathbf{J}$ Gynecol Obstet. 2012;116(3):263-4.

11. Tanha FD, Salimi S, Ghajarzadeh M. Sublingual versus vaginal misoprostol for cervical ripening before hysteroscopy: a randomized clinical trial. Arch Gynecol Obstet. 2013;287(5):937-40.

12. Hua Y, Zhang W, Hu X, Yang A, Zhu X. The use of misoprostol for cervical priming prior to hysteroscopy: a systematic review and analysis. Drug Des Devel Ther. 2016;10:2789-2801.

Cite this article as: Gupta T, Ahmad SN, Kumari S. Comparative study of efficacy and adverse effects of different doses of vaginal misoprostol for cervical ripening 10-12 hours before diagnostic hysteroscopy. Int J Reprod Contracept Obstet Gynecol 2018;7:1065-9. 